\title{
Making sporting clubs healthy and welcoming environments: A strategy to increase participation
}

\author{
Rochelle M. Eime*, Warren R. Payne, Jack T. Harvey
}

School of Human Movement and Sport Sciences, University of Ballarat, Victoria, Australia

Received 3 August 2006; received in revised form 13 November 2006; accepted 1 December 2006

\section{KEYWORDS}

Healthy and welcoming

environments;

Sporting clubs;

Sport participation

\footnotetext{
* Corresponding author.

E-mail address: r.eime@ballarat.edu.au (R.M. Eime).
}

\begin{abstract}
Summary Sporting clubs are an ideal setting to promote community-wide participation in physical activity. Using the principles of the Ottawa Charter as a guide, this study explored the factors affecting the development of supportive environments as a mechanism to increase participation in club sport. The Victorian Health Promotion Foundation (VicHealth) funds State Sporting Associations (SSAs) to develop healthy and welcoming environments (HWE) in their associated clubs. The program focus areas are: welcoming and inclusive environments, sports injury prevention, 'smoke-free' environments, responsible serving of alcohol, sun protection and healthy eating. This paper sought to determine whether or not SSA Executive Officers (EOs) believe that the creation of a supportive environment will facilitate sporting club membership and to identify the factors that affect the development of the HWEs. Forty-two (82.4\%) of the 51 funded SSAs completed a general survey and $36(70.6 \%)$ of EOs responded to questions that were specifically addressed to them. EOs from six SSAs also participated in semi-structured interviews. SSA EOs (97.2\%) believed that the creation of HWE in clubs would facilitate increases in participant membership. However, the data indicate incomplete development of the HWE focus areas at the club level because of limited club capacity and limited SSA support. Reportedly, the SSAs are at the stage of raising program awareness at the club level. It is suggested that SSAs should plan a structured approach to the development of HWEs that acknowledges the diverse capacity of their clubs, and garner the support of key club volunteers in order to establish HWEs.

Crown Copyright $\odot 2007$ Published by Elsevier Ltd on behalf of Sports Medicine Australia. All rights reserved.
\end{abstract}

\section{Introduction}

VicHealth was established in 1987 and has worked closely with the sporting community since that time to promote good health. A key group funded 
by VicHealth are the State Sporting Associations (SSAs). SSAs are responsible for the conduct and development of their respective sports across the state of Victoria. In 2001, VicHealth adopted a approach to increase participation in sport. ${ }^{1}$ One objective was explicitly to promote structural reform in SSAs and their affiliated associations and clubs via the implementation of policies and practices to establish healthy and welcoming club environments (HWEs). ${ }^{2}$ Crisp and Swerissen (2003) investigated a program to implement these reforms in sporting clubs using a case study approach. ${ }^{3}$ They reported a number of examples where communitybased sporting clubs were positively influenced to implement HWE policies and practices.

Following this program, VicHealth implemented the Partnerships for Health (PfH) Scheme. ${ }^{4}$ Under the PfH scheme, more than A\$ 3 million is allocated annually to SSAs (51 in 2003, 49 from 2004) for the 3-year period covering the 2003-2004 to 2005-2006 financial years. The overall scheme objectives are to establish a health-promoting environment in sporting clubs, improve the capacity of SSAs to understand and promote the link between sport and health (capacity-building) and conduct sport-specific participation programs in settings such as schools and sporting clubs, so as to achieve the goal of increasing the membership of sporting clubs within Victoria. ${ }^{4}$ The focus on the link between health-promoting club environments and sports participation recognised both the important health benefits that can be derived from participation in physical activity, and that SSAs and their clubs are keenly interested in growing their participant membership base.

VicHealth has established six focus areas in which HWE club practices and policies will be developed. These are: welcoming and inclusive environments; sports injury prevention or risk management; responsible serving of alcohol; smoke-free environments; healthy eating; sun protection. ${ }^{4}$

The creation of a HWE club as a means of promoting participation in sport is an innovation in keeping with good health promotion practice, as outlined in the Ottawa Charter and the Jakarta Declaration. ${ }^{5,6}$ In particular, two of the principles of the Ottawa Charter are to build healthy public policy and to create supportive physical and social environments ${ }^{5}$; while the Jakarta Declaration highlights the need to secure an infrastructure for health promotion. ${ }^{6}$ The promotion of healthy or supportive environments is founded on the constructs contained within social learning theory ${ }^{7}$ and the social ecological approach to public health. ${ }^{8}$
The promotion of physical activity through the creation of supportive physical and social environments and policy is based upon the evidence of the efficacy of these approaches. ${ }^{9,10}$ While these studies explored the determinants of participation in unstructured physical activity, no research has been identified that has explored whether or not the creation of a supportive environment is a key factor affecting structured physical activity as reflected in sporting club membership. Other than the preliminary data of Crisp and Swerissen, ${ }^{3}$ no data were identified that defined the key factors that impede or facilitate the adoption of supportive environments in a sporting setting. Therefore, as an initial step towards this goal, the purpose of the current study was to determine whether or not key stakeholders believe that creation of a supportive environment will facilitate sporting club membership, and to determine the factors that facilitate or limit the creation of supportive environments in sporting clubs.

\section{Methods}

Fifty-one VicHealth-funded SSAs were approached to complete a web-based survey in 2004. The study was approved by the University of Ballarat Human Research Ethics Committee. The survey sought to obtain information on whether or not the Executive Officers (EOs) of the respective SSAs believed that the development of HWEs would facilitate increased club membership. Further, the survey was used to gather data on the presence of HWE policies and practices in the SSAs and their affiliated clubs, and the influence of the SSA on the development of HWEs in their clubs. The decision of each SSA as to whether to focus on HWE policies or practices was also investigated. The survey gathered data on five of the six HWE focus areas. The exception was the welcoming and inclusive focus area, for which VicHealth had not established minimum standards. SSA staff were provided with unique usernames and passwords to ensure confidentiality. The responses were downloaded into an Excel ${ }^{\mathrm{TM}}$ spreadsheet and analysed using SPSS $^{T M}$ software. The responses to open-ended questions were classified post hoc into themes using content analysis. ${ }^{10}$ Further exploration of the HWE program occurred through face-to-face interviews with EOs from six SSAs. The six SSAs were chosen from a stratified sample in accordance with the quantum of VicHealth funding, number of members, gender of participants and general age of participants (Table 1). The semi- 


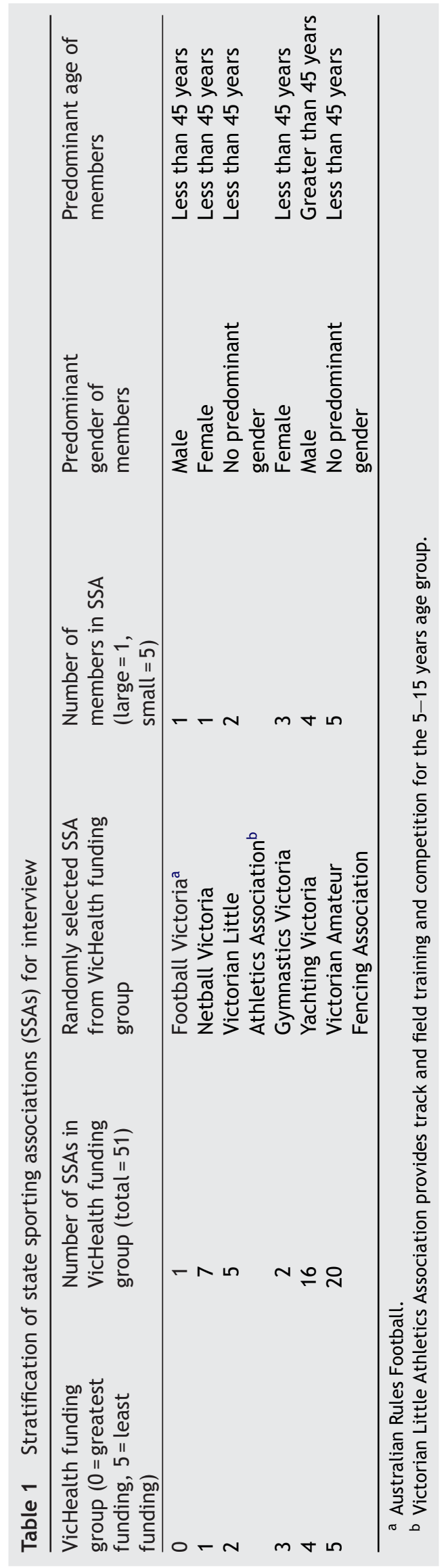

structured interviews explored the principles on which the HWE program was based, the development of the HWE program, influence of the SSA on club HWE-related practices and policies, HWE program barriers, facilitators and priorities. The interviews were audio taped and transcribed. The key themes were identified using content analysis. ${ }^{11}$

\section{Results and discussion}

Traditionally, SSAs have focused directly on maximising participation in their respective sports through development of specific participation programs and competition formats, and not upon facilitating participation via indirect strategies such as development of HWEs. Organisations responsible for facilitating health promotion such as VicHealth, nevertheless, view sporting clubs as appropriate settings for health promotion, as participation in sport is associated with physical, mental and social health benefits and there is potential to reach many people. ${ }^{12-14}$ Despite the potential to achieve health benefits through sport participation, some sporting clubs may have or had an unhealthy image. One SSA EO stated: "I think sport needs to change its image that if you are successful you need to then go and get blind rotten drunk and I hate that."

The first aim of this study was to determine whether or not the SSAs believed that the creation or development of HWEs would facilitate an increase in participation and membership in their sport. Of the 36 EOs who responded to the webbased survey, $97.2 \%$ believed that the creation of a HWE in clubs would act as a facilitator to increase membership in their sport, with $77.8 \%$ strongly agreeing with this statement. No respondent disagreed with this statement. In general, these data provide an important first step towards understanding the factors that affect the creation of HWEs and their impact upon sport participation and club membership. One EO commented that HWEs and participation were "integrated objectives; you won't build participation without good environments and there is no sense in building good environments unless you have got good healthy participation within them'". In this sense it is apparent that the SSAs appear to have linked the concepts of club development and the provision of HWEs. This is an important development since the EOs are key stakeholders in determining sport policy and club support and development programs. As such they are important enablers to the creation of HWEs within clubs. ${ }^{15}$ For some SSAs the 
VicHealth HWE club program is incorporated into a club development program which also includes club management structures and strategies.

The second aim of the study was to determine the actual HWE practices and policies, SSA influences on clubs and program facilitators and barriers. In order to explore this issue, the SSAs completed the relevant components of the webbased survey. The response rate to the survey was $82.4 \%$. Table 2 presents a summary of the results gained from the web-based survey of the 51 SSAs funded by VicHealth under the PfH Scheme.

Although the EOs expressed a belief that the creation of a HWE would result in increased participation and club membership, it is concluded that SSAs have limited capacity to influence the activities of individual clubs. In most cases, sporting clubs in Victoria are affiliated with SSAs but are not compelled to comply with directives from the SSAs, except for SSA-sanctioned events held at clubs. The lack of power to mandate change and limited capacity to monitor change at the club level present the SSAs with a challenge, given their contractual obligation to VicHealth to effect such change. To date, very little research has been published that has explored the capacity of state or national professional sport leaders to create change at the level of the volunteer-based affiliated sporting club. In particular, to our knowledge, there are no published data concerning the capacity of governing sporting bodies to affect practices within sporting clubs designed to improve membership via the creation of HWEs.

Even though many SSA EOs understand the rationale for HWEs, the impact of the VicHealth HWE program at the club level was spasmodic. Most SSAs reported that they had policies across all of the HWE focus areas for activities for which they were directly responsible such as State championships. A smoke-free policy was reportedly in place for all SSA-directed activities and events, and most had a policy available for clubs $(n=36,87.8 \%)$. This was not unexpected, given the Victorian smoking legislation banning smoking in public places and the role of agencies such as The Cancer Council Victoria and their QUIT program. The coverage of this focus area may be expanded further if clubs had access to a standardised smoke-free policy template from their SSA. Another important finding regarding the adoption of HWEs is that despite the existence of a strong legal framework governing the serving of alcohol, only half of the SSAs believed that all their clubs complied with Liquor Licensing Victoria regulations.

One reason for the spasmodic introduction of the HWEs at the club level was that certain focus areas are proving harder to implement than others. In particular, the 'healthy eating' and 'welcoming and inclusive environments' were reported to be difficult focus areas to implement (Table 3). For example, many club canteens are open once or twice per week and the short shelf life of fresh food meant many clubs experiencing difficulty in providing healthy eating options. One EO stated: "A lot of the healthy food options are ones which have short shelf life ... so we make sure that we have a balance, a variety." The cost of healthy food is also reported to be a problem for clubs and therefore, financially as well because, practically, processed rather than fresh food is much easier and cheaper to supply. These findings reinforce the findings of Crisp and Swerissen ${ }^{3}$ in a pilot study of this program, who found that healthy catering was the area for which sporting organisations sought most support. Similarly, the study of Dobbinson and Hayman ${ }^{12}$ into healthy sporting clubs also reported a low rate of policy development in the area of healthy eating. The HWE focus area of welcoming and inclusive environments was described as lacking structure. It was stated that "the hard one to implement the program is the welcoming environment. It seems a bit vague. I don't think there is enough guidance. The concept is a good idea but implementation is a bit random."

For the sun protection focus area, the availability of sunscreen at clubs was the most commonly reported practice $(n=6,15.0 \%)$. Little influence on clubs from their SSA was reported, apart from policy development $(n=8,18.6 \%)$ and the dissemination of newsletters and information $(n=7$, 16.3\%). An SSA EO commented that the clubs were encouraged to apply for VicHealth sunshade grants, and to run activities at certain times of the day: "We actually reinforce the fact that we encourage centres to apply for grant funds or invest their own funds in sun shade structures ... and to actually schedule activities at the appropriate time of the day." The extent of the perceived club sports injury prevention or risk management practices were largely the availability of educational material $(n=12,22.2 \%)$ and policies being developed $(n=6,11.1 \%)$.

In a general sense, the limited capacity of clubs to implement HWE policies and practices and the general lack of support given by the SSAs to their respective clubs were two of the most common barriers reported to the implementation of HWE club practices and policies. It was apparent that one of the principal reasons why some focus areas are more developed than others is that insufficient time has elapsed for SSAs and clubs to understand and adopt the raft of new concepts, policies and prac- 


\begin{tabular}{|c|c|c|c|c|}
\hline HWE focus area ${ }^{a}$ & $\begin{array}{l}\text { Policy developed for } \\
\text { SSA directed activities } \\
\text { and events }\end{array}$ & $\begin{array}{l}\text { SSA has a policy } \\
\text { developed for } \\
\text { clubs }\end{array}$ & $\begin{array}{l}\text { Unprompted SSA statement of their } \\
\text { influence on clubs }\end{array}$ & SSA perception of club practices \\
\hline $\begin{array}{l}\text { Smoke- } \\
\text { free }\end{array}$ & $\begin{array}{l}n=41 \\
100 \%\end{array}$ & $\begin{array}{l}n=36 \\
87.8 \%\end{array}$ & $\begin{array}{l}\text { SSA developed policy: } n=8 \text { (20\%) } \\
\text { Distribute educational material to } \\
\text { clubs: } n=17(42.5 \%)\end{array}$ & $\begin{array}{l}\text { All clubs facilities smoke-free: } \\
n=18(26.1 \%) \\
\text { Clubs do not sell tobacco: } n=6 \\
(8.7 \%) \\
\text { Smoke-free signs present: } n=6 \\
(8.7 \%) \\
\text { All clubs are } 100 \% \text { smoke-free } \\
\text { indoors: } n=22(53.7 \%)\end{array}$ \\
\hline Responsible serving of alcohol & $\begin{array}{l}n=34 \\
85.0 \%\end{array}$ & $\begin{array}{l}n=26 \\
65.0 \%\end{array}$ & $\begin{array}{l}\text { SSA developed policy: } n=15(32.6 \%) \\
\text { Educational resources available: } \\
n=11(23.9 \%) \\
\text { General promotion: } n=11(23.9 \%)\end{array}$ & $\begin{array}{l}\text { Adhere to Liquor Licensing Victoria } \\
\text { regulations: } n=7(15.2 \%) \\
\text { SSA policy in place at clubs: } n=6 \\
(13.0 \%) \\
\text { SSAs believe that all clubs comply } \\
\text { with Liquor Licensing Victoria } \\
\text { regulations: } n=22(52.5 \%)\end{array}$ \\
\hline $\begin{array}{l}\text { Sports injury prevention or risk } \\
\text { management }\end{array}$ & $\begin{array}{l}n=30 \\
75 \%\end{array}$ & $\begin{array}{l}n=27 \\
67.5 \%\end{array}$ & $\begin{array}{l}\text { Provide courses: } n=4(13.8 \%) \\
\text { Injury prevention ('Smartplay') } \\
\text { newsletter, educational } \\
\text { material/information, posters and } \\
\text { manuals provided: } n=3(10.4 \%)\end{array}$ & $\begin{array}{l}\text { Educational material provided: } \\
n=12(22.2 \%) \\
\text { Club policies developed: } n=6 \\
(11.1 \%)\end{array}$ \\
\hline Sun protection & $\begin{array}{l}n=22 \\
53.7 \%\end{array}$ & $\begin{array}{l}n=17 \\
41.5 \%\end{array}$ & $\begin{array}{l}\text { SSA developed policy: } n=8(18.6 \%) \\
\text { Newsletters/information provided: } \\
n=7(16.3 \%)\end{array}$ & $\begin{array}{l}\text { All clubs have sunscreen available: } \\
n=6(15 \%)\end{array}$ \\
\hline Healthy eating & $\begin{array}{l}n=31 \\
77.5 \%\end{array}$ & $\begin{array}{l}n=25 \\
62.5 \%\end{array}$ & $\begin{array}{l}\text { SSA developed policy: } n=14(31.1 \%) \\
\text { Information available: } n=9(20.0 \%)\end{array}$ & $\begin{array}{l}\text { Offer healthy options: } n=20 \\
(35.7 \%) \\
\text { Club policies developed: } n=5 \\
(8.9 \%)\end{array}$ \\
\hline
\end{tabular}


Table 3 State sporting association (SSA) healthy and welcoming environments (HWE) interview results

\begin{tabular}{|c|c|c|}
\hline Area & Theme & Interview results $(n)$ \\
\hline \multirow[t]{3}{*}{ HWE facilitators } & - Understanding of benefits & $\begin{array}{l}\text { - Understanding by clubs that the benefits of HWE include } \\
\text { increased participation at clubs } \\
\text { - HWE fits perfectly with our organisation's objectives (2) }\end{array}$ \\
\hline & - Attitude of club & $\begin{array}{l}\text { - Clubs appreciate the HWE } \\
\text { - Some clubs are proactive }\end{array}$ \\
\hline & - Encouragement & - SSA providing incentives to clubs (2) \\
\hline \multirow[t]{3}{*}{ HWE barriers } & $\begin{array}{l}\text { - Attitude of club } \\
\text { - Lack of understanding and } \\
\text { guidance }\end{array}$ & $\begin{array}{l}\text { - Some clubs are not proactive } \\
\text { - The 'welcoming and inclusive environment' area is hard } \\
\text { to understand and implement } \\
\text { - There is not enough guidance or structure for the } \\
\text { implementation of HWE }\end{array}$ \\
\hline & $\begin{array}{l}\text { - Limited formal uptake of } \\
\text { policies }\end{array}$ & $\begin{array}{l}\text { - It is difficult for clubs to adopt the policies } \\
\text { - Clubs not accepting the established policies in the } \\
\text { minutes of their meetings }\end{array}$ \\
\hline & - Logistical difficulties & $\begin{array}{l}\text { - The healthy eating area is affected by limited shelf life } \\
\text { and the cost of healthy, fresh food }\end{array}$ \\
\hline \multirow[t]{4}{*}{ General } & $\begin{array}{l}\text { - Relationship to club } \\
\text { objectives }\end{array}$ & $\begin{array}{l}\text { - Clubs need to realise the need for, and benefits of, HWE } \\
\text { (2) } \\
\text { - At this stage HWE is about club awareness (3) }\end{array}$ \\
\hline & $\begin{array}{l}\text { - Uncertainty as to } \\
\text { appropriate strategy for } \\
\text { introduction of HWEs into } \\
\text { clubs }\end{array}$ & $\begin{array}{l}\text { - The priority of HWE is getting policies in place } \\
\text { - HWE is more about practices than it is about policies }\end{array}$ \\
\hline & $\begin{array}{l}\text { - HWEs can assist to improve } \\
\text { sport's image within the } \\
\text { community }\end{array}$ & $\begin{array}{l}\text { - Sport needs to change its image } \\
\text { - SSA wants to up-skill and provide resources to their clubs } \\
\text { so that they can be self-supportive }\end{array}$ \\
\hline & - Logistical support & \\
\hline
\end{tabular}

tices. However, once the principles were outlined and adopted, SSAs were more likely to encourage the adoption of HWE practices $(n=29,82.9 \%)$ than the development of policies $(n=6,17.1 \%)$. It appears that this approach reflects the pragmatic, non-bureaucratic, 'do it now' approach taken by many sporting clubs. One SSA explained that, for it, HWE was "more about practices, that they are practising healthy welcoming environment' .

There is also considerable variation in the rate at which the HWE focus areas are introduced into SSAs and their clubs; with some SSAs focusing on all HWE areas at once while others adopt one or two at a time. The question arises from the results as to whether or not such variation in the process of introducing HWE practices is appropriate. The answer to this question probably resides in the capacity of SSAs and clubs to accomplish these developments. In clubs with limited capacity to develop and implement policy, it may be best to focus on a staged introduction of HWE practice fol- lowed by the development of policy, and not to focus on all areas at once. This was the case in the Good Sports Responsible Serving of Alcohol program, where it was only at the fourth stage that policy development and the implementation of a written code of conduct was expected. ${ }^{16}$ A potential solution to the problem of limited club capacity was proposed by Dobbinson and Hayman (2002) who reported that the establishment of a written policy by a club was often dependent on having a designated person responsible for club policy development. Furthermore, the problems experienced with developing healthy club policies generally related to a need for more training, advice and resources to assist with policy development and monitoring. ${ }^{12}$

When asked what the SSAs do to influence or assist the development of club HWEs, the most common responses related to the provision of educational material or to the development by the SSA of a policy that the clubs could adopt. However, this is still not a common practice. Similarly, Dob- 
binson and Hayman reported that sample policies were the most common form of support received by clubs. ${ }^{12}$ Some of the SSAs supported clubs by providing them with templates and direction as well as incentives to become involved and specific funding opportunities. A view was expressed that SSAs should provide materials that make it easier for clubs to adopt a HWE: "materials that they are not going to have to reinvent the wheel and it's easy to adopt." Therefore, there was general support for SSAs supporting clubs by establishing standardised policies and practice recommendations. Such support was also seen as "(taking) away the constant need for new decision making (at clubs), because the decision has already been made for them." The provision of such a support role was also recommended by Crisp and Swerissen who commented that SSAs should develop a policy and document the process for implementing policy and promoting the required structural change to member clubs/affiliates. ${ }^{3}$ It was also noted that some SSAs have adopted incentives for clubs in order to overcome barriers for clubs implementing HWE policies and practices. Some of the incentives provided by SSAs include practical items such as first aid kits or recognition awards.

In keeping with the views expressed by the SSA EOs in general, one EO explained that some clubs were beginning to understand the HWE principles, and that there was a belief that, if clubs adopt the HWE practices, they will in turn be "more likely to attract people." Despite the presence of awareness-raising and education, there appeared to be a general absence of a wellstructured process to support the transformation from awareness-raising to club-based behaviour change. This is evidenced by the limited influence of SSAs on clubs for each of the HWE focus areas. A variety of planning frameworks are available to guide this change. ${ }^{17}$ In a general sense, it seems that aspects of Pettigrew's Contextualist approach 18 are relevant to the change associated with the introduction of the HWE concept in to sporting clubs, as this approach "incorporates the interrelated role over time of environment (context), structure and human agents in shaping the change process'. ${ }^{17}$ More specifically, a possible framework to guide the stages of change associated with the introduction of the HWE concept is that developed by Griener. ${ }^{19}$ This framework identifies stages that see an organisation move from 'pressure and arousal' to 'reinforcement and acceptance'.

An insight into the potential for the SSA to lead such cultural and structural change may be gleaned from the work of Amis et al. (2004). These authors explored the role of sub-unit interests, power arrangements and organisational capacity in a program of radical transformation of Canadian National Sporting Organisations. ${ }^{15}$ Though acknowledging the broad range of sporting organisations and their level of specialisation, formalisation and centralisation, they concluded that the capacity of organisations to change was affected by the interests of the organisational sub-unit, the distribution of power and overall capacity to change. While it is acknowledged that this study considered change at a national level, the results may indicate that any attempt by the SSAs to influence the behaviour and activities of their affiliated clubs (sub-units) will need to acknowledge and work to use these factors as facilitators to change. In terms of the processes identified by Amis et al. ${ }^{15}$ EOs wishing to effect change at the club level need to convince the club leaders that the adoption of HWEs is in their political self-interest and that the change is not an attempt by the SSA to 'take over' the clubs. In this case, political self-interest may be best served by couching the establishment of HWEs within a club development framework. In particular, the Canadian experience was most successful when change was gradual and undertaken using a partnership approach to establish trust between the respective organisations. This process can be assisted by the SSAs and EOs creating both a clear vision for the future and providing the clubs with the technical means to bring about the desired change and to operate effectively in the changed state. ${ }^{15}$ In general, neither of these is being provided at the moment in support of the introduction of HWEs into Victorian sporting clubs.

Given that change in sporting organisations is highly affected by key individuals, ${ }^{15}$ it might be useful to characterise the process in terms of the Transtheoretical model. ${ }^{20}$ The model describes behaviour change in five stages, in relation to readiness to change. The stages are: pre-contemplation, contemplation, preparation, action and maintenance. Individuals move through these stages at various rates and sometimes move back and forth before reaching the maintenance stage. ${ }^{20}$ In terms of the Transtheoretical model, it is apparent that these key individuals are affected by emotions, cognitions and behaviours, as in the Transtheoretical model. It is also apparent that these key individuals at the club level may have been moved from the pre-contemplation to contemplation stage by the awareness-raising strategies, but there has been little or no attention paid to the preparation, action or maintenance phases of the change process. It appears that the clubs are beginning to realise that the development of HWEs is in their self-interest but 
they lack the capacity to undertake the development.

It is apparent, therefore, that an overriding factor affecting the capacity of clubs to enact change and the potential for success of the HWE program is the presence or absence of planning by the SSA to achieve the desired structural change. There is evidence, however, that some SSAs have undertaken structural change and have developed and implemented club development programs utilising a staged approach model. Crisp and Swerissen reported that SSAs often do not plan to achieve structural change, ${ }^{3}$ and they suggested that ideally the structural planning by the SSA would involve developing a policy, documenting the process for implementing policy and promoting the required structural change to member clubs. Furthermore, they stated that few, if any, details on how structural change would be implemented were provided by the SSAs. This is not dissimilar to the situation reported for the implementation of the current HWE program. In general, there is limited guidance from VicHealth to the SSAs regarding how the change process surrounding the introduction of the HWE program within the SSA and at the club level could be managed or implemented in order to achieve the contracted outcome. When planning structural change, the diverse capacity of SSAs and clubs to adopt and implement new processes and programs also needs to be considered. Crisp and Swerissen reported that structural change in a club setting was often not found to be tailored to fit the varying capacity and structure of the sponsored organisations. ${ }^{3}$ In addition to SSAs considering the diversity of their clubs, funding bodies need to recognise the differing capacity of SSAs, and even the varying nature of the form and extent of communication between SSAs and their clubs. The capacity for SSAs to implement all of VicHealth's focus areas of structural change at the one time may be limited. ${ }^{3}$ Trying to focus on the development of all focus areas at once may be extremely difficult for many SSAs given the time span of the VicHealth $\mathrm{PfH}$ scheme and the current capacity of sporting clubs. Therefore, the application of uniform minimum standards to all SSAs irrespective of their size, structure and overall capacity would seem inappropriate. It is apparent that a staged approach to the introduction of the various HWE focus areas may be appropriate. While it must be recognised that some SSAs and their clubs have successfully adopted a staged approach to the introduction of HWEs, this approach is not common practice.

In conclusion, many SSAs now recognise that clubs focusing solely on participation programs in an unsafe or unwelcoming environment are unlikely to entice people to become club members. They believe that the newly developed focus on HWE clubs will result in increases in participant membership in their sports. However, this cannot be done without planning for cultural and structural change understanding the diverse capacity of clubs to deliver participation and implement HWE programs, and monitoring and evaluating the program both at the SSA and club levels. SSAs are at the stage of building the awareness of this new approach with their associated clubs. It is recommended that VicHealth should assist the SSAs in developing strategies to implement HWE club practices and policies. It is also recommended that VicHealth should consider a staged approach, in accordance with the capacity of the SSAs and clubs. Future research should monitor the progression of the HWE program throughout Victorian sporting clubs and test the accepted assumption that the creation of HWE clubs will result in increases in sport participant membership.

\section{Practical implications}

- Sporting organisations should structurally plan for all programs.

- Sports funding bodies need to understand the differing capacity of the sporting organisations that they fund.

- Club development programs/practices can assist with increased club participation.

- Sporting organisations have limited capacity and power to mandate changes in clubs.

- Funding bodies need to give guidance to organisations when setting new program philosophies.

\section{Acknowledgements}

This study was funded by VicHealth, as a component of the VicHealth Sport and Active Recreation Schemes Evaluation Project. Staff from VicHealth are thanked for their overall contribution to the administration of this research. We thank the SSA staff for their contribution to this project.

\section{References}

1. Victorian Health Promotion Foundation. VicHealth annual report 2001-2002. Melbourne; 2002.

2. Victorian Health Promotion Foundation. VicHealth annual report 2002-2003. Melbourne; 2003. 
3. Crisp BR, Swerissen H. Critical processes for creating health-promoting sporting environments in Australia. Health Promot Int 2003;18(2):145-51.

4. Victorian Health Promotion Foundation. Partnerships for health scheme (2003-2006). Funding guidelines. Melbourne; 2003.

5. World Health Organisation. The Ottawa Charter for Health Promotion, available at http://www.who.int/hpr /NPH/docs/ottawa_charter_hp.pdf; 1986 [accessed November 2005].

6. World Health Organisation. The Jakarta Declaration on health promotion in the twenty first century, available at: http://www.who.int/hpr/NPH/docs/jakarta _declaration_en.pdf; 1997 [accessed November 2005].

7. Bandura A. In: Cliffs E, editor. Social Learning Theory. NJ: Prentice Hall; 1977.

8. Stokols D, Allen J, Bellingham R. The social ecology of health promotion: implications for research and practice. Am J Health Promot 1996;10(4): 247-51.

9. Brownson RC, Baker EA, Housemann RA, et al. Environmental and policy determinants of physical Activity in the United States. Am J Public Health 2001;91.(12).

10. Duncan M, Spence J, Mummery K. Perceived environment and physical activity: a meta-analysis of selected environmental characteristics. Int J Behav Nutr Phys Act 2005;2(11):1-9.

11. Miles M, Huberman M. Qualitative data analysis. 2nd ed. Thousand Oaks: SAGE Publications; 1994.
12. Dobbinson S, Hayman J. VicHealth healthy sports clubs study: a survey of structures, policy and practice. Melbourne: The Cancer Council Victoria; 2002.

13. Jackson N, Howes F, Gupta S, et al. Policy interventions implemented through sporting organisations for promoting healthy behaviour change. The Chochrane database of systematic reviews, no. 2; 2005, Art. No. CD004809.pub2. doi:10.1002/14651858.CD004809.pub2.

14. Department of Human Services. Victorian burden of disease study-mortality and morbidity in 2001. Melbourne: Victorian Government Department of Human Services; 2001.

15. Amis J, Slack T, Hinings C. Strategic change and the role of interests, power and organizational capacity. J Sport Manage 2004;18:158-98.

16. Australian Institute for Primary Care: Centre for Development and Innovation in Health. Evaluation of the good sports accreditation program. Melbourne: La Trobe University; 2003.

17. Slack T. Understanding sport organizations. Adelaide: Hum Kinet; 1997.

18. Pettigrew A. In: Lawler E, editor. Contextualist research: a natural way to link theory and practice. Doing research that is useful in theory and practice. San Fancisco: JosseyBass; 1985. p. 222-48.

19. Griener L. Patterns of organizational change. Harvard Bus Rev 1967;45:119-30.

20. Procheska J, Di Clemente C. Stages and processes of selfchange of smoking: towards an integrative model of change. J Consult Clin Psychol 1983;51:390-5. 